\title{
Online Voting - Not Only a Technical Challenge
}

\author{
PIA KARGER \\ Federal Ministry of the Interior, D-11014 Berlin, pia.karger@bmi.bund.de
}

\begin{abstract}
This paper is about the challenge of online voting. First it illustrates why we should put effort into this subject, and it describes the security requirements which have to be achieved. Then it discusses an approach to achieve online voting step by step, and evaluates experiences gathered in pilot projects being conducted so far. Further on the German discussion on online voting is reflected, and it is emphasised that online voting is not at all only a technical challenge. More interdisciplinary research and a widespread public discussion is needed, which could be reached e.g. by a technology assessment. The last section gives a short prospect to e-democracy on the whole, and why online voting has to be embedded there.
\end{abstract}

Keywords: online voting, information technology security, stepwise approach, technology assessment, e-democracy

\section{THE SUBJECT OF ONLINE VOTING}

Our democracy is based on our citizens" participation in political processes. Particularly regarding the often diagnosed disenchantment with politics and the increasing non-transparency of structures and processes of political decision making, the potentials offered by the internet have to be used, to strengthen the opportunities for all to participate in political processes - and thereby to strengthen the opportunities for stimulating our democracy.

In this paper participation is understood in a manner, which is mainly directed to strengthen opportunities for political information, for the exchange of political opinions and for political decisions (voting and elections). This paper focuses on the challenge of online voting only.

So far, political elections have taken the form of voting at polling stations or - in some countries like Germany or Switzerland - elections by postal

\footnotetext{
The original version of this chapter was revised: The copyright line was incorrect. This has been corrected. The Erratum to this chapter is available at DOI: 10.1007/978-0-387-35617-4_48 
ballot. Why should it not be possible to cast votes in online elections in the future?

"Online voting" can be defined as an electronically arranged election process, which allows voting via networks independently of place of (registered) residence (cf Landesamt für Datenverarbeitung und Statistik Brandenburg 2000). Casted votes are transmitted to an electronic ballot-box via net. Often the terms "online voting" and "internet voting" are used as synonyms. More precisely "internet voting" names the medium which is used for data transmission, for "online voting" also an intranet could be used (Kubicek/Wind 2002:93).

To discuss online voting appropriately, a comprehensive examination would be needed. At least the aspects shown in figure 1 are involved.

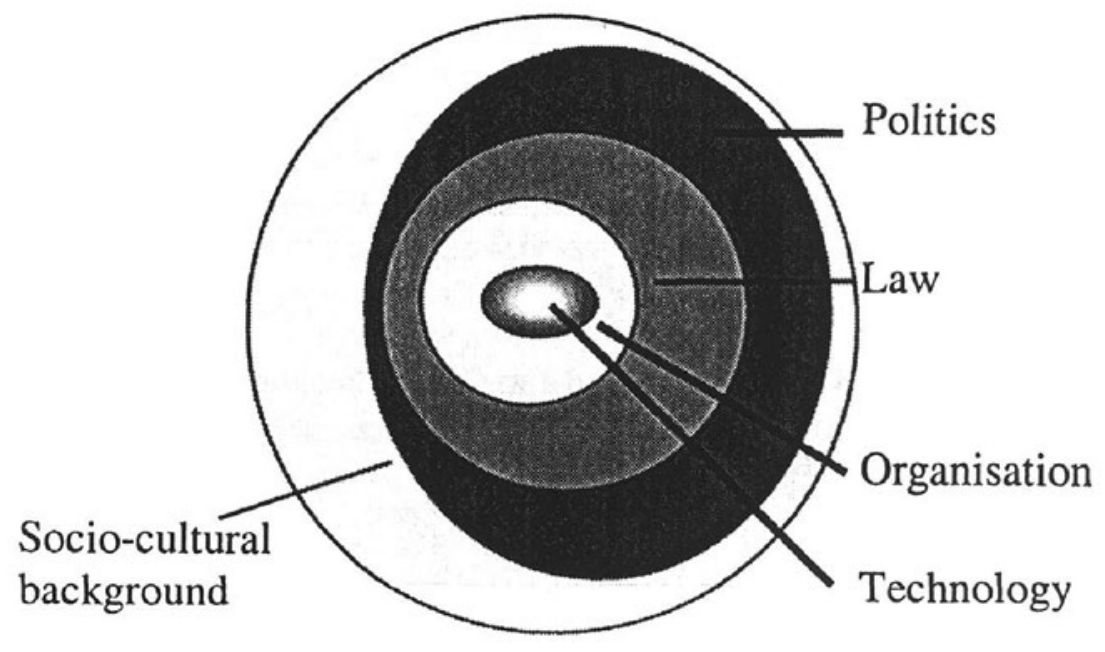

Figure 1: Aspects of online voting

Some arguments in favour of online elections are:

- Online elections are considered a way of vote-casting which is appropriate in a mobile society. The rising number of postal voters in Germany (nation wide average of $15 \%$, in cities up to nearly $30 \%$ at the last election of the German Parliament 1998 (Buchstein 2002:61)) speaks for itself.

- Electronic votes can be counted much more rapidly.

- Through technical support it could be possible to avoid some of the invalid votes that might have been cast inadvertently in the past. This has become evident when electoral equipment (electoral devices) was used in some German cities (cf Stadt Köln 2001).

- Accessibility is another important goal: Technical support should be designed to enable disabled persons, to cast their votes without having to rely on help from others. 
Sometimes, expectations are raised with regard to online voting in terms to increase turn-out of elections and to reduce people's disenchantment with politics. However, a lack of political interest or a low turn-out at elections would seem to have other reasons than the alleged idleness of citizens. ${ }^{1}$

\section{SECURITY REQUIREMENTS}

At first glance, online balloting seems to be as easy as postal voting. However, political elections are not merely expressions of one's opinion which can be sent over the internet without any security measures ${ }^{2}$. For democratic legitimacy of anyone who holds sovereign powers, strict compliance with electoral principles under constitutional law $^{3}$ is absolutely necessary. Therefore, online election procedures must fulfil demanding requirements in terms of reliability as well as in efficiency.

Preconditions for online voting are technical systems and organisational processes which render fraud impossible, which are protected reliably against attacks and failures, and which fulfil high requirements under constitutional law in terms of general, direct, free, equal and secret ballots. These electoral principles may not be changed at all, if we put an "E-" in front of voting and use electronic media for this purpose.

Election systems must be designed especially so as to ensure

- that solely voters who are clearly identified and authentified as "entitled to vote" can cast their votes,

- that every voter can cast her/his vote only once and that this vote is only counted once,

1 Hoecker (2002) points out that according to critical voices the thesis that new media support participation could be based on the wrong assumption that earlier nonparticipation was mainly a technical problem. According to Hoecker there are no reliable empirical results for turn-outs of elections and votings in the net today.

2 To deal with the essential trait of information technology security a comprehensive concept (cf e.g. Hartmann 1998, Hartmann/Karger 2001) should be taken as a basis. At least the following levels have to be included:

- technical and technological elements of IT-security, i.e. availability, integrity and confidentiality,

- organisational elements,

- legal and economical elements, i.e. questions of legal compatibility and efficiency, as well as

- social and ecological elements, i.e. questions of social vulnerability and dependence on workable information technology,

- the cultural background, that means questions of security culture, i.e. the perception of chances and risks of information technology.

3 The electoral principles based on the constitutional law are explained e.g. by Rüß (2000), Rüß (2001), Holznagel/Hanßmann (2001). 
- that the vote cast is kept secret permanently - and this really means "for ever", ${ }^{4}$

- that manipulations during the entire election process including the counting of votes are impossible both during data transmission and storage,

- that the system is available on election day.

In particular, the combination of "unambiguous authentification of the voter" and "secrecy of the voting decision" - ensured at the same time - is not a trivial task.

Intensive discussions and research are being conducted on how these requirements can be met (Cf e.g. Grimm 2001a, Grimm 2001b, Ullmann/ Koob/Kelter 2001). Without such security, voters will not trust the new technical opportunities, and will not use them either. Only if it can be ensured that citizens have confidence in the correctness of elections and their results and the procedure is accepted, online elections can be justified. ${ }^{5}$

\section{AN APPROACH TO ACHIEVE ONLINE VOTING}

For this reason, the German Federal Ministry of the Interior has set up a working group which analyses the requirements and conditions of online elections (cf Karger 2002).

In a dialogue with computer specialists, legal experts and organisers of elections, the working group analyses

- requirements in terms of functionality and security of technical election systems,

- the legal frameworks for their approval as well as

- the criteria for the organisation of online elections resulting from the use of technology.

4 According to Ullmann/Koob/Kelter (2001) no process is known, which can assure the high degree of anonymity of votes for an unlimited period of time.

5 With Buchstein (2001:153) already a security problem (falsely) feared by a sufficient number of voters is enough to undermine the legitimacy of online election. 


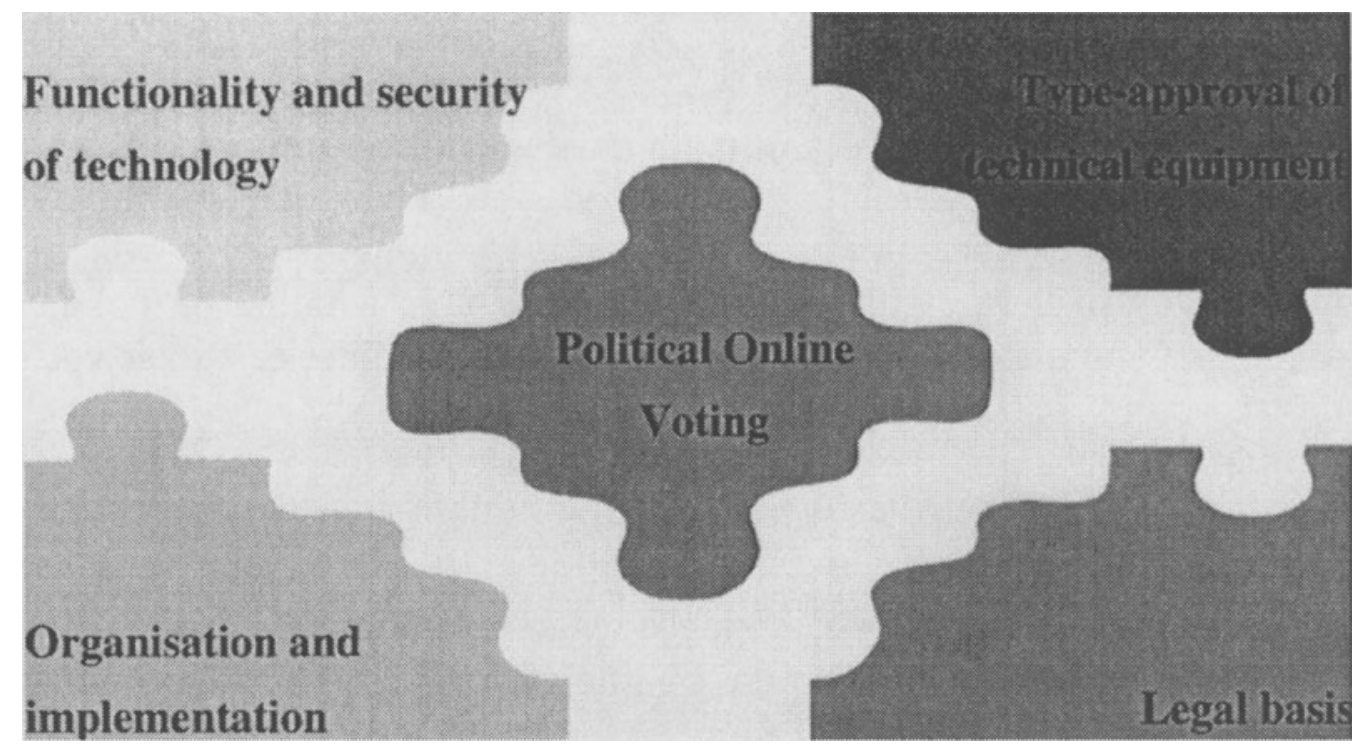

Figure 2: Task areas to analyse the subject of political online voting

Figure 2 shows that a strong interaction between these task areas is needed.

According to US experts online elections by use of private PCs should be offered as the very last step in a graded approach: In 1999 the White House directed the National Science Foundation (NSF) to proceed a study on internet voting. With the report - published in March $2001^{6}$ - internet voting systems falls into three categories: poll site voting, kiosk voting and remote voting. For poll site voting or kiosk voting security problems are mainly solvable with the available technology. But remote voting (in which citizens could vote from any terminal, e.g. at home or work) poses substantial security issues ${ }^{7}$ in addition to other risks. Therefore it should not be used in public elections until substantial technical and social science issues are addressed. In contrast poll site voting could be responsibly deployed within the next several election cycles.

The German Federal Ministry of the Interior also follows a graded approach, guided by experience, which initially should submit electronic voting in a networked polling station. A second step could consist in elections from special public internet terminals (e.g. kiosks) before

6 Internet Policy Institute (2001), also see California Internet Voting Task Force (2000), Caltech/MIT Voting Technology Project (2001).

${ }^{7}$ Grimm (2001b) points out, that it is very difficult to avoid individual cases of manipulated home PCs reliably. The only way to achieve non-manipulated voting terminals securely, is the use of public voting terminals in polling stations. 
electronic voting could, in a third step, be made possible from any internet access (cf Karger 2002).

On the basis of electronic voting in a networked polling station, elections at any arbitrary polling station could be possible. Then, voters will have the opportunity to cast their votes not only in the polling district in which they reside but also in any other polling station. Voters who are on holiday on polling day (and still are within the voting area) need not cast their votes by postal voting, but will then also be able to cast their votes in a polling station.

For this first stage of networked polling stations some issues still require clarification (cf Kubicek/Karger/Wind 2002):

- Polling stations must be equipped with type-approved technology for electronic voting, and in some polling stations access to the internet or another network must first of all be established.

- Access to all electoral registers from any polling station might become necessary. For this purpose, substantial technical and organisational integration efforts will be needed, because the electoral registers are maintained very differently in the various German municipalities.

- And finally there is the question of the necessary funding and of current costs.

\section{WHAT CAN BE LEARNED FROM PILOT PROJECTS}

In pilot projects experience has been gathered concerning online elections in various fields of application. With the "elections on the internet" project launched by the German Federal Ministry of Economics and Technology in the spring of 1999 , the technical preconditions had been created for an election via internet in Germany for the first time. The online election system " $i$-vote" ${ }^{\text {"8 }}$ developed in this process was tested in two realistic simulations ("social elections" of the Techniker Krankenkasse (health insurance fund) in 1999, elections to the Staff Council of the Landesamt für Datenverarbeitung und Statistik Brandenburg in June $2000^{\circ}$ ) as well as the legally valid elections to the students ' parliament of Osnabrück University in February 2000.

In Germany in the second half of 2001, for instance, local Youth Councils in the two cities Esslingen ${ }^{10}$ and Fellbach ${ }^{11}$ and the Academic

8 Cf http://www.internetwahlen.de/projekt/index.html

9 In May 2002 a legal valid election to the Staff Council followed this simulation (cf http://www.brandenburg.de/evoting).

${ }^{10} \mathrm{Cf}$ http://www.jgrwahl.esslingen.de/ 
Senate and the Faculties ' Councils at Bremerhaven University ${ }^{12}$ were elected online, the city of Cologne tested an election system for the election of the senior citizens ' representation ${ }^{13}$, and interested postal voters in the Landkreis Marburg-Biedenkopf were able to participate in an online test election to the chief executive officials of this county ${ }^{14}$.

In order to discuss the approaches and results of these projects, the second workshop on "online elections", organised by the Federal Ministry of the Interior in co-operation with the D21 initiative ${ }^{15}$, and prepared by the Study Group "Telecommunications" of Bremen University, was held in December 2001 (cf Kubicek/Karger/Wind 2002).

While the first type of this event in September 2000 served to develop the exchange of information and views between election organisers, suppliers of technical equipment and legal experts, the goal of the second workshop was to discuss and learn from the approaches and results of pilot projects that had been conducted in the meantime.

The discussions showed that there are not only legal and organisational hurdles, but that there is still a great need of technical development:

- Various technical solutions are available to substantiate "the citizen's right to vote"; they are based either on transmitted keys (e.g. PIN/TAN combinations) or on the use of electronic signatures. Identification by means of entered key combinations has the advantage of easy handling, but might facilitate the purchase or sale of votes. By contrast, a voter would not very likely hand out his/her personal signature (card).

- The protection against attacks by third parties continues to be a weakness, particularly (distributed) denial-of-service attacks pose a great risk.

11 Cf http://www.fellbach.de/wahlen/

12 Cf http://www.hs-bremerhaven.de/

13 Cf http://www.koeln.de/news/bereich1/artikel.php3/1614/uebersicht.html/900/30/uebersicht.html

14 Cf http://www.marburg.de/esi/index.html

15 The Deutschland21 initiative is an association of renowned companies with the aim of speeding up the transition from an industrial to an information society in Germany. This is done in co-operation with politics. The Advisory Board of this initiative is headed by Federal Chancellor Gerhard Schröder. The work is done in working groups each headed by one representative from politics and one from the business community. Their aims include:

- Policy-makers, the business community, scientists and society develop optimum frameworks for the transition to the information age

- The state and its institutions set good examples in the use of modern technologies

- The state and the business community promote the acceptance of new information technologies. 
- Effective security measures against manipulations from within - e.g. by the administrators of an online election system - are also necessary. ${ }^{16}$

Beside these technical issues, it became apparent how difficult it is to ensure the same degree of transparency and verifiability of election results, compared with our known election process. Greater attention must also be paid to operability and user-friendliness both for the voters and for the election board members. It also became apparent that we should to a greater extent focus on organisational aspects as well as on cultural background and political framework.

\section{NOT AT ALL ONLY A TECHNICAL CHALLENGE}

Technological chances must not be a practical constraint - the design of election processes continues to be a political task. Regarding figure 1 the approach must not only be from inside to outside but also (at least) vice versa. ${ }^{17}$ Until today the technical modelling of vote-casting was in the centre of research in Germany. Not the characteristics of a technology itself, but its socio-cultural embedding determines the manner and degree of its use. Therefore questions of political and social science regarding our understanding of voting and democracy must also come into the main focus.

In Germany there are a few voices which discuss rather non-technical aspects. Let me refer to some examples:

- Buchstein (2001) mentions the possibility of online voting as a gateway for direct-democratic forms of politics, and discusses a possible trend to a "push-button-democracy".

- Neymanns (2002) stresses the symbolic function of elections. One component is that elections take place in public. With voting from private PCs the casting of votes would be transferred from public to private sphere. Buchstein (2001 and 2002) therefore points out the lack of legitimacy by constitutional law and the threatening cancellation of the obligatory secret balloting by online voting from private PCs.

- The issues of a digital divide in terms of internet access and media competence and the influence of online-voting on voter's behaviour were discussed e.g. during the Workshop Internet-Voting (2002).

16 The EU project "Cybervote" (http://www.eucybervote.org/) follows an interesting approach. Its intention is to reflect the principle of greater scrutiny (4-eyes-principle) of the electoral board. Each member of the electoral Board possesses a part of the decryption key with which the overall result - but not individual votes ! - can be decrypted.

17 Kubicek/Wind (2001) describe four options of connecting online elections in a broad context, which are named as "content-motivational", "socio-cultural", "legal-institutional" and "technical-organisational" context. 
Further relevant issues are e.g. how online voting shall be embedded in the existing context of voting, and how acceptance of online voting and trust in voting procedures arises.

Not only technological possibilities but also those issues must eventually determine the political decision about online voting. Therefore a stronger interdisciplinary co-operation between social and technological sciences and a more widespread public discussion is needed.

Both can be achieved e.g. by conducting a technology assessment, which has been shown to be an adequate method to assess, to describe and to predict possible interdependencies. During the process direct and indirect as well as short-, middle- and long-term effects as well as desired and undesired results are assessed. In this process their consequences are evaluated, possibly existing legal, economical or social conflicts are identified, design options are developed and alternative action options are shown. A discursive technology assessment process allows an open exchange between all disciplines of sciences involved and all social groups potentially affected, which aims to understanding, but not necessarily to consensus (cf Karger 1999). Thus a technology assessment should lead to an evaluation of these issues and initiate and support a discourse in society on its whole.

It will only be at the very end of this intensive process that we will be in a position to decide responsibly whether online voting in political elections can be implemented in accordance with our Constitution and in a technically secure and economically reasonable manner. We should work to achieve this, however not at any speed and any price, but at a secure pace.

\section{PROSPECT TO E-DEMOCRACY ON THE WHOLE}

Elections - as the expression of the political will - are preceded by the forming of this will. Information and discussion are two important elements in this forming process, and we have to use the chances of the internet also in those fields: The added value of online elections manifests itself particularly clearly in the electronic triad "informing, discussing and voting" (figure 3). 


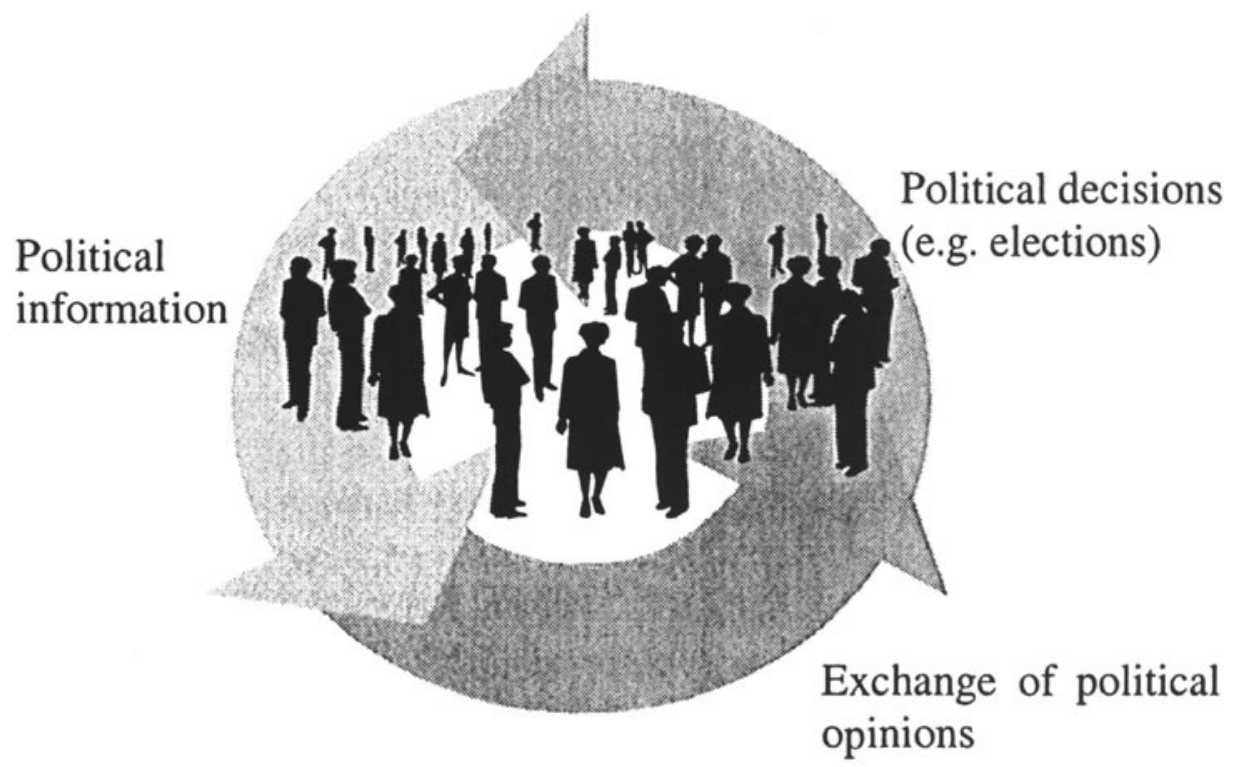

Figure 3: The electronic triad "informing, discussing and voting"

Information is the precondition for political involvement of citizens and serves as a basis for the forming of individual political opinions. This is followed by the exchange of political opinions (e.g. in discussions). For both the internet offers a new quality, regarding information access and communicative interaction.

The internet's potential in overcoming citizens' disenchantment with politics seems to lie in its capacity of rendering political processes more transparent. Information and discussion forums on the internet can help to achieve this, and can at the same time form a basis for voting decisions.

It would be basically irresponsible not to use the internet for our democracy. We would leave a media unattended which is actually used by an ever-increasing number of citizen. The internet offers great chances to strengthen the democratic involvement of citizens. We must not pass up this opportunity.

\section{REFERENCES}

Buchstein, Hubertus. "Modernisierung der Demokratie durch e-Voting?". Leviathan (Zeitschrift für Sozialwissenschaft) Sonderdruck Westdeutscher Verlag 2001; 2:147-155.

Buchstein, Hubertus. "Online-Wahlen und das Wahlgeheimnis." In Online-Wahlen, Buchstein, Hubertus, Neymanns, Harald (Hrsg.), Opladen 2002; 51-70.

California Internet Voting Task Force, A Report on the Feasibility of Internet Voting. Sacramento CA 2000; www.ss.ca.gov/executive/ivotel.

Caltech/MIT Voting Technology Project, Residual votes Attributable to Technology. An Assessment of the Reliability of Existing Voting Equipment. Cambridge/Mass 2001.

Grimm, Rüdiger. "Security Requirements for Internet Voting". ACM Multimedia Security Workshop; October 2001; Ottawa 2001a; 1-4. 
Grimm, Rüdiger. "Technische Sicherheit bei Internetwahlen - Anmerkungen aus Sicht der Informationstechnik." In Elektronische Demokratie - Bürgerbeteiligung per Internet zwischen Wissenschaft und Praxis, Holznagel, Bernd, Grünwald, Andreas, Hanßmann, Anika (Hrsg.), Schriftenreihe Information und Recht, Band 24, München 2001b; 86-104.

Hartmann, Anja. "Security Culture in the Global Information Society". In Global IT-Security, Papp, György, Posch, Reinhard (ed.), Wien 1998; 484- 490.

Hartmann, Anja, Karger, Pia. "Modern Learning for a Secure Information Society". Proceedings of the International Conference on Information and Communication Technologies for Education EDICT 2000; 2000 December 6-9 ${ }^{\text {th }}$ Vienna. Riedling, Eveline, Davies, Gordon (eds.), Österreichische Computer Gesellschaft 2000; 193-200.

Hoecker, Beate. "Fördert das Internet die Demokratie?". Frankfurter Rundschau online 08.02.2002; www.f-r.de.

Holznagel, Bernd, Hanßmann, Anika. "Möglichkeiten von Wahlen und Bürgerbeteiligung per Internet". In Elektronische Demokratie - Bürgerbeteiligung per Internet zwischen Wissenschaft und Praxis, Holznagel, Bernd, Grünwald, Andreas, Hanßmann, Anika (Hrsg.), Schriftenreihe Information und Recht, Band 24, München 2001; 55-72.

Internet Policy Institute, Report of the National workshop on Internet Voting: Issues and Research Agenda, sponsored by the National Science Foundation. Washington D.C. 2001; http://www.internetpolicy.org/research/results.html.

Karger, Pia. "IT-Sicherheitskompetenz - Qualifizierung für IT-Sicherheit". In IT-Sicherheit ohne Grenzen?, Bundesamt für Sicherheit in der Informationstechnik (Hrsg.), Tagungsband 6. Deutscher IT-Sicherheitskongreß des BSI 1999, Ingelheim 1999; 327 341.

Karger, Pia. "Online-Wahlen im Dreiklang der e-Demokratie". In Neue und bewährte Applikationsfelder der Chipkarte, Matthias Fluhr (Hrsg.), Dokumentation des Kongresses OMNICARD 2002, Berlin 2002; 156-158.

Kubicek, Herbert, Karger, Pia, Wind, Martin. "Online Wahlen - Stilles Wettrennen". Kommune21 2002; 4:12-13.

Kubicek, Herbert, Wind, Martin. "Elektronisch Wählen. Unterschiede und Gemeinsamkeiten von Online-Wahlen zum Studierendenparlament und zum Bundestag". Verwaltung und Management. Zeitschrift für allgemeine Verwaltung 2001; 3:132-141.

Kubicek, Herbert, Wind, Martin. "Bundestagswahl per Computer?". In Online-Wahlen, Buchstein, Hubertus, Neymanns, Harald (Hrsg.), Opladen 2002; 91-112.

Landesamt für Datenverarbeitung und Statistik Brandenburg, Bericht zur Personalratswahlsimulation via Internet. Potsdam 2000.

Neymanns, Harald. "Die Wahl der Symbole: Politische und demokratietheoretische Fragen $z$ u Online-Wahlen". In Online-Wahlen, Buchstein, Hubertus, Neymanns, Harald (Hrsg.), Opladen 2002; 23-37.

Rüß, Oliver René. "Wahlen im Internet - Wahlrechtsgrundsätze und Einsatz von digitalen Signaturen". MMR 2000, 2:73-76.

Rüß, Oliver René. "E-democracy - Demokratie und Wahlen im Internet". Zeitschrift für Rechtspolitik 2001, 11:518-521.

Stadt Köln. "Elektronisch wählen in Köln!". 2001; http://www.koeln-wahlen.de/_fs/fs_elekw. htm.

Ullmann, Markus, Koob, Frank, Kelter, Harald. "Anonyme Online-Wahlen - Lösungsansätze für die Realisierung von Online-Wahlen". Datenschutz und Datensicherheit 2001, 11:643647.

Workshop Internet-Voting. Present forms and future perspectives. IPSA RC 05: Comparative studies of local government and politics. Institute for Political Science, University of Marburg; 2002 June 14-15; unpublished discussion. 